\title{
A Brain on Cannabinoids: The Role of Dopamine Release in Reward Seeking
}

\author{
Erik B. Oleson ${ }^{1}$ and Joseph F. Cheer ${ }^{1,2}$ \\ ${ }^{1}$ Department of Anatomy and Neurobiology, University of Maryland School of Medicine, Baltimore, \\ Maryland 21201 \\ ${ }^{2}$ Department of Psychiatry, University of Maryland School of Medicine, Baltimore, Maryland 21201 \\ Correspondence: jchee001@umaryland.edu
}

\begin{abstract}
Increases in mesolimbic dopamine transmission are observed when animals are treated with all known drugs of abuse, including cannabis, and to conditioned stimuli predicting their availability. In contrast, decreases in mesolimbic dopamine function are observed during drug withdrawal, including cannabis-withdrawal syndrome. Thus, despite general misconceptions that cannabis is unique from other drugs of abuse, cannabis exerts identical effects on the mesolimbic dopamine system. The recent discovery that endogenous cannabinoids modulate the mesolimbic dopamine system, however, might be exploited for the development of potential pharmacotherapies designed to treat disorders of motivation. Indeed, disrupting endocannabinoid signaling decreases drug-induced increases in dopamine release in addition to dopamine concentrations evoked by conditioned stimuli during reward seeking.
\end{abstract}

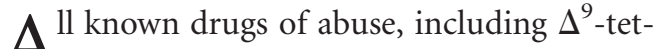

Arahydrocannabinol, the primary psychoactive component of Cannabis sativa, increase dopamine concentrations in terminal regions of the mesolimbic dopamine system (Di Chiara and Imperato 1988; Pierce and Kumaresan 2006). The mesolimbic dopamine system is a neural pathway that originates from A10 dopamine neurons in the ventral tegmental area of the midbrain and projects to limbic structures, most prominently the nucleus accumbens ( $\mathrm{Ta}-$ ble 1) (Spanagel and Weiss 1999). Increases in nucleus accumbens dopamine are theorized to mediate the primary positive reinforcing and rewarding properties of all known drugs of abuse (Roberts et al. 1977; Wise and Bozarth
\end{abstract}

1985; Ritz et al. 1987). In addition, when animals are presented with conditioned stimuli that predict drug availability, transient dopamine events that are theorized to mediate the secondary reinforcing effects of drugs of abuse and initiate drug seeking are also observed in the nucleus accumbens (Phillips et al. 2003; Owesson-White et al. 2009). In contrast, the negative affective state that occurs during drug withdrawal is associated with a decrease in mesolimbic dopamine function, which might lead to compulsive drug seeking (Weiss et al. 2001; Koob 2009). This article reviews studies addressing the effects of cannabinoids and cannabinoid withdrawal on dopamine release, in addition to the effects of manipulating the

Editors: R. Christopher Pierce and Paul J. Kenny

Additional Perspectives on Addiction available at www.perspectivesinmedicine.org

Copyright (C) 2012 Cold Spring Harbor Laboratory Press; all rights reserved; doi: 10.1101/cshperspect.a012229

Cite this article as Cold Spring Harb Perspect Med 2012;2:a012229 
E.B. Oleson and J.F. Cheer

Table 1. Terminology and definitions used in text

\begin{tabular}{|c|c|}
\hline Terminology & Definition \\
\hline Cannabinoids & $\begin{array}{l}\text { Pharmacologically defined as a class of chemical compounds-comprising } \\
\text { phytocannabinoids, chemically synthesized cannabinoids, and } \\
\text { endocannabinoids-that bind to the cannabinoid CB1/CB2 receptor. }\end{array}$ \\
\hline Primary reinforcer & $\begin{array}{l}\text { An event that increases the probability of a behavioral response. In the context } \\
\text { of drug addiction, an injection of heroin or a toke on a pipe might function } \\
\text { as a primary reinforcer. }\end{array}$ \\
\hline Secondary reinforcer & $\begin{array}{l}\text { Also referred to as a "conditioned cue," a stimulus that acquires reinforcing } \\
\text { properties through Pavlovian associations. In the context of drug addiction, } \\
\text { a syringe or a pipe might function as a secondary reinforcer. }\end{array}$ \\
\hline Negative reinforcer & $\begin{array}{l}\text { An event that increases the probability of a behavioral response resulting in the } \\
\text { elimination or avoidance of the event. }\end{array}$ \\
\hline Tonic dopamine & $\begin{array}{l}\text { A steady-state dopamine level arising from dopamine neurons firing at low } \\
\text { frequency }(1-5 \mathrm{~Hz}) \text { that is capable of occupying high-affinity dopamine } \\
\text { D2 receptors. }\end{array}$ \\
\hline Phasic dopamine & $\begin{array}{l}\text { A significant, transient increase in dopamine concentration arising from } \\
\text { dopamine neurons firing in high-frequency bursts }(\geq 20 \mathrm{~Hz}) \text { that is capable } \\
\text { of occupying low-affinity dopamine D1 receptors. }\end{array}$ \\
\hline Microdialysis & $\begin{array}{l}\text { In the context of in vivo neurochemistry, a semipermeable probe is inserted } \\
\text { into a brain region, artificial cerebral spinal fluid is infused, and dialysate } \\
\text { containing neurotransmitters that passively diffuse into the probe is } \\
\text { extracted and analyzed. }\end{array}$ \\
\hline $\begin{array}{l}\text { Fast-scan cyclic } \\
\quad \text { voltammetry }(\mathrm{FSCV})\end{array}$ & $\begin{array}{l}\text { In the context of in vivo neurochemistry, a carbon fiber microelectrode is } \\
\text { inserted into a brain region, and voltage is applied to the carbon fiber, } \\
\text { resulting in the oxidation of surrounding chemicals; the resulting current } \\
\text { flow is detected and analyzed. }\end{array}$ \\
\hline Nucleus accumbens & $\begin{array}{l}\text { A component of the basal ganglia that is commonly divided into two } \\
\text { substructures, the core and the shell. All known drugs of abuse increase } \\
\text { dopamine concentrations in the nucleus accumbens. }\end{array}$ \\
\hline Ventral tegmental area & $\begin{array}{l}\text { A group of neurons within the midbrain that are primarily dopaminergic } \\
(>50 \%) \text { and contribute to the mesocortical and mesolimbic dopamine } \\
\text { pathways. }\end{array}$ \\
\hline $\begin{array}{l}\text { Mesolimbic dopamine } \\
\text { system }\end{array}$ & $\begin{array}{l}\text { A dopaminergic pathway in the brain that projects from A10 dopamine } \\
\text { neurons in the VTA to limbic structures including the nucleus accumbens, } \\
\text { amygdala, hippocampus, and medial prefrontal cortex. }\end{array}$ \\
\hline
\end{tabular}

endogenous cannabinoid system on drug- and cue-evoked dopamine release.

\section{TONICAND PHASIC DOPAMINE OVERVIEW}

Before delving into the interaction between cannabinoids and the dopamine system, it is important first to develop a general understanding of the patterns of dopamine signaling and the common methods used to monitor dopamine transmission in vivo. Two distinct patterns of dopamine neural activity occur in the behaving animal. Midbrain dopamine neurons typically fire at low frequencies of $1-5 \mathrm{~Hz}$, which is thought to produce a tone on high-affinity dopamine D2 receptors in terminal regions of the mesolimbic dopamine system, including the nucleus accumbens (Grace 1991; Dreyer et al. 2010). These tonic dopamine levels are detectable using techniques, such as in vivo microdialysis, that allow for neurochemical collection on a timescale of minutes. In contrast, when animals are presented with motivationally salient stimuli, such as conditioned cues that predict drug availability, midbrain dopamine neurons fire in high-frequency bursts $(\geq 20 \mathrm{~Hz})$, 
thereby producing transient increases in nucleus accumbens dopamine concentration that are sufficiently high to occupy low-affinity dopamine D1 receptors (Grace 1991; Phillips et al. 2003; Dreyer et al. 2010). These phasic dopamine events are detectable in vivo at the level of the dopamine neuron using single-unit electrophysiological recording techniques or at the neurochemical level within terminal fields of the mesolimbic dopamine system using fast-scan cyclic voltammetry, an electrochemical technique that allows for the detection of dopamine on the millisecond timescale.

\section{CANNABINOIDS INCREASE TONIC DOPAMINE LEVELS}

A long-held misconception was that cannabinoids, such as $\Delta^{9}$-tetrahydrocannabinol, fail to increase dopamine concentrations in the same manner as other drugs of abuse (Wickelgren 1997). This point was even disputed in the experimental literature; for example, a single edition of the journal Pharmacology, Biochemistry, and Behavior contained contrasting reports on whether cannabinoids increase dopamine levels in the brain (cf. Gardner and Lowinson 1991 vs. Castaneda et al. 1991). Currently, however, the existence of an overwhelming body of neurochemical evidence $(\mathrm{Ng}$ Cheong Ton et al. 1988; Chen et al. 1990, 1991, 1993; Tanda et al. 1997; Malone and Taylor 1999) unequivocally shows that cannabinoids do, indeed, increase dopamine concentrations in the nucleus accumbens. It should be noted, however, that genetic factors partially determine the magnitude of cannabinoid-induced increases in accumbal dopamine concentration (Gardner 2002, 2005), because Gardner and colleagues (Chen et al. 1991) reported that the dopamine-increasing potency of cannabinoids varies depending on the strain of rat assessed. Importantly, these cannabinoid-induced increases in nucleus accumbens dopamine are most prominently observed in the shell region of the nucleus accumbens and occur in a cannabinoid CB1 receptor-dependent manner. As illustrated in Figure $1 \mathrm{~A}$, the cannabinoid $\mathrm{CB} 1$ receptor agonist WIN55,212-2 increased dopamine concentra- tions within the nucleus accumbens shell, an effect that was blocked by the coadministration of the cannabinoid CB1 receptor antagonist rimonabant. Cannabinoid-induced increases in nucleus accumbens dopamine concentration are thought to arise from an increase in the mean firing rate of dopamine neurons within the ventral tegmental area. In accordance with this theory, using single-unit recording techniques, multiple reports indicate that cannabinoids increase the firing rate of ventral tegmental area dopamine neurons (French 1997; French et al. 1997; Gessa et al. 1998; Wu and French 2000). These parallel increases in cannabinoidinduced neural activity are shown in Figure 1B; specifically, WIN55,212-2 dose-dependently increased the frequency of dopamine neural firing (Gessa et al. 1998). Importantly, also, the cannabinoid-induced increases in dopamine neural activity were abolished following administration of rimonabant, which shows that cannabinoids increase dopamine neural activity through a CB1 receptor-dependent mechanism.

\section{CANNABINOIDS INCREASE PHASIC DOPAMINE EVENTS}

The majority of the aforementioned neurochemical studies measured changes in tonic dopamine levels using in vivo microdialysis. To assess whether cannabinoids increase phasic dopamine release events, Cheer et al. (2004) measured nucleus accumbens dopamine concentrations in the behaving rat using fast-scan cyclic voltammetry. As illustrated in Figure 1C, WIN55,212-2 increased the frequency of phasic dopamine events detected in the nucleus accumbens shell (Cheer et al. 2004). Rather than resulting from the regular pacemaker firing that characterizes tonic dopamine signaling (e.g., Fig. 1B), these transient increases in accumbal dopamine release are thought to arise from high-frequency bursts of dopamine neural activity (Gonon 1988; Sombers et al. 2009). As would be predicted, therefore, Figure 1D shows that the cannabinoids $\Delta^{9}$-tetrahydrocannabinol and WIN55,212-2 both increased the frequency of bursts in addition to the number of impulses 
Tonic dopamine

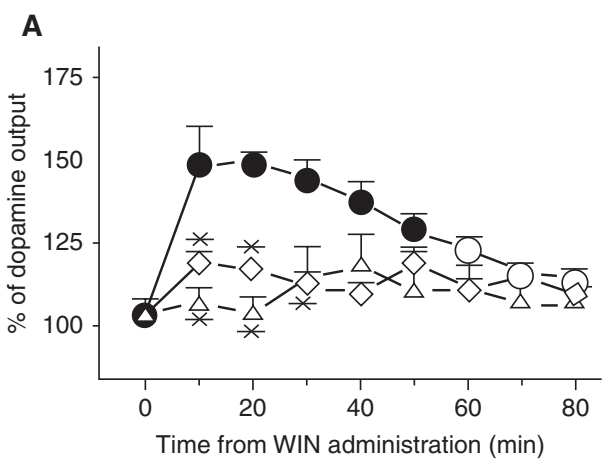

B

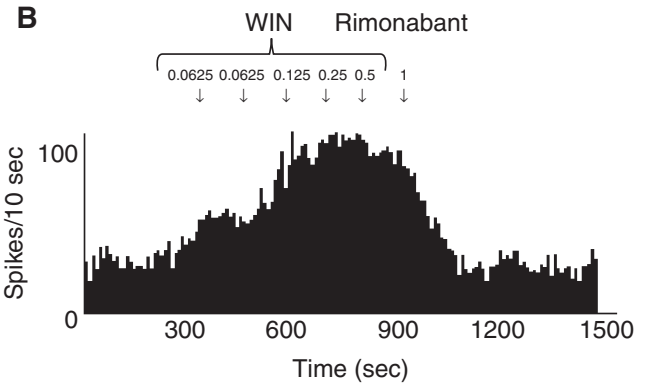

Phasic dopamine

C

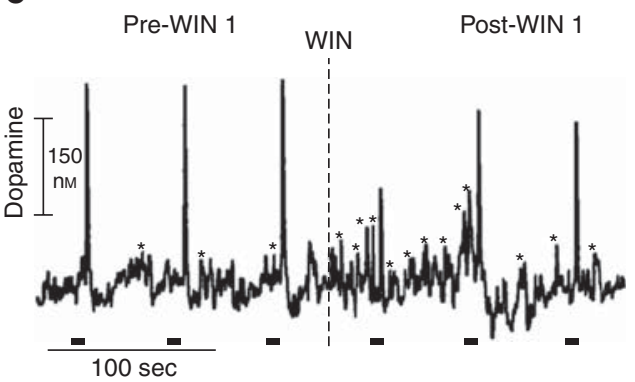

D

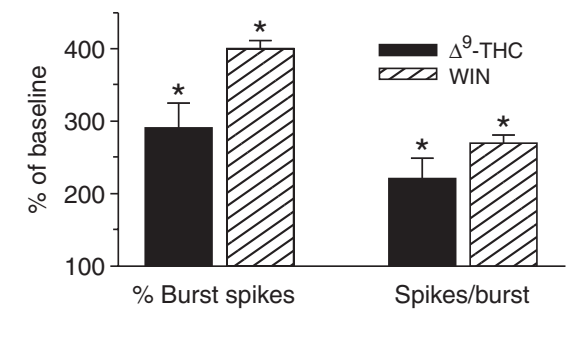

Figure 1. Cannabinoids increase tonic and phasic dopamine release. $(A)$ The cannabinoid CB1 receptor agonist WIN55,212-2 (0.3 mg/kg i.v., filled circles) increased tonic dopamine concentrations in the shell region of the nucleus accumbens in comparison to vehicle (open parallelograms). The cannabinoid CB1 receptor antagonist rimonabant ( $1 \mathrm{mg} / \mathrm{kg}$ s.c., open triangles) prevented the WIN-induced increase in accumbal dopamine concentration. (Figure constructed from data by Tanda et al. 1997.) (B) WIN55,212-2 dose-dependently increased the neural activity of an antidromically identified ventral tegmental area dopamine neuron. Rimonabant reversed the WIN-induced increase in dopamine neural activity. (Figure constructed from data by Gessa et al. 1998.) (C) WIN55,212-2 (0.125 mg/kg i.v., right of dashed line) increased the frequency of phasic dopamine events detected in the shell region of the nucleus accumbens in comparison to pre-treatment (left of dashed line) values. To assess for cannabinoid-induced changes in dopamine uptake, dopamine release was evoked by electrical stimulation (0.4-sec duration, $60 \mathrm{~Hz}, \pm 120 \mu \mathrm{A}$, black bars) applied to the medial forebrain bundle. WIN55,212-2 failed to increase the width of electrically evoked dopamine events, suggesting that cannabinoids do not increase nucleus accumbens dopamine by decreasing dopamine uptake. (Figure constructed from data by Cheer et al. 2004.) (D) $\Delta^{9}$-Tetrahydrocannabinol (filled bars) and WIN55,212-2 (open bars with coarse diagonal fill) increased phasic dopamine neural activity. Both cannabinoids increased the number of bursting events observed and the number of impulses occurring per burst. $\left(^{*}\right)$ A significant difference versus predrug levels. (Figure constructed from data by Gessa et al. 1998.)

occurring during each burst of dopaminergic neural activity (Gessa et al. 1998).

\section{PHARMACOLOGICAL MECHANISMS OF CANNABINOID-INDUCED INCREASES IN DOPAMINE}

After determining that cannabinoids increase both tonic and phasic dopamine neurotransmis- sion, investigators began addressing the pharmacological mechanisms involved. Initially, in vitro synaptosomal studies suggested that cannabinoids might increase nucleus accumbens dopamine concentrations, in part, by binding to the dopamine transporter and thereby decreasing uptake into presynaptic terminals (Hershkowitz and Szechtman 1979; Poddar and Dewey 1980), which would be consistent 
with the pharmacological mechanism of action of other drugs of abuse, such as cocaine. If cannabinoids increase dopamine concentration by decreasing uptake, however, the width of electrically evoked dopamine release events should increase when assessed using in vivo FSCV. Electrically evoked dopamine events result in high concentrations of dopamine that saturate dopamine transporters, thus allowing changes in uptake to be discerned. As illustrated in Figure 1C, cannabinoids failed to alter the width of electrically evoked dopamine release events, thereby showing that cannabinoids do not increase dopamine by decreasing uptake (Cheer et al. 2004). Furthermore, dopamine uptake inhibitors typically decrease neural firing of dopamine neurons by activating inhibitory dopamine D2 autoreceptors (Einhorn et al. 1988). Thus, a cannabinoid-induced decrease in dopamine uptake would be inconsistent with a cannabinoid-induced increase in dopamine neural firing (Fig. 1B). Another possibility is that cannabinoids might directly stimulate dopamine neurons; however, this hypothesis is also unlikely, because of multiple reports that dopamine cell bodies lack cannabinoid CB1 receptors (Herkenham et al. 1991; Julian et al. 2003). An alternative model, proposed by Carl Lupica (Lupica and Riegel 2005), suggests that cannabinoids might increase dopamine release by indirectly disinhibiting dopamine neurons. In support of this model, application of cannabinoids to ventral tegmental area brain slices decreased GABAergic inhibitory postsynaptic currents in $\mathrm{GABA}_{\mathrm{A}}$ receptor-dependent manner (Szabo et al. 2002) and failed to increase dopamine neural activity following pre-treatment of $\mathrm{GABA}_{\mathrm{A}}$ receptor antagonists (Cheer et al. 2000). Taken together, in support of Lupica's model, these data suggest that cannabinoids increase dopamine neural firing by decreasing GABAergic inhibition of dopamine neural activity.

\section{DOPAMINE LEVELS ARE DECREASED DURING CANNABIS WITHDRAWAL}

A key feature of the addiction phenomenondrug withdrawal-is theorized to produce a negative emotional state that drives persistent, relapsing drug seeking (Childress et al. 1988; Koob et al. 1998). It is now well accepted that withdrawal occurs in association with a decrease in mesolimbic dopamine function (Weiss et al. 2001). For example, when experimental animals are withdrawn from drugs of abuse (e.g., ethanol, morphine, cocaine, and amphetamine), decreased tonic dopamine concentrations are detected in the terminal regions of the mesolimbic dopamine system when assessed using in vivo microdialysis (Rossetti et al. 1992; Weiss et al. 1992, 1996). Although the use of cannabinoids, such as marijuana and hashish, was historically considered to be devoid of withdrawal symptoms (Todd 1946), we now know that cannabinoids do, indeed, produce clinically significant withdrawal symptoms. Over the course of several clinical studies (Jones et al. 1976; Budney et al. 1999; Haney et al. 1999), investigators documented a "cannabis-withdrawal syndrome," which is composed of several core symptoms, including anxiety/nervousness, decreased appetite/weight loss, restlessness, sleep difficulties including strange dreams, chills, depressed mood, stomach pain/physical discomfort, shakiness, and sweating (Budney and Hughes 2006). It is likely, therefore, that these withdrawal symptoms contribute to cannabis dependence through negative reinforcement processes. The development of animal models of cannabis-withdrawal syndrome allowed for the investigation of the neural mechanisms involved. To date, two distinct models of cannabis withdrawal exist (Lichtman and Martin 2002). The first, involving abrupt forced abstinence from experimenter-administered cannabinoids (e.g., $\Delta^{9}$-tetrahydrocannabinol, WIN55,212-2), results in mild withdrawal symptoms that are relatively difficult to detect (Aceto et al. 1996, 2001). The second, involving precipitated withdrawal induced by a rimonabant challenge, results in immediately observable robust withdrawal symptoms (e.g., wet dog shakes) (Aceto et al. 1995; Tsou et al. 1995). The behavioral manifestations of precipitated cannabinoid withdrawal are accompanied by a decrease in ventral tegmental dopamine neural activity as assessed using single-unit recording techniques (Diana et al. 1999). The decreased dopamine 
neural activity occurs along the same time course as decreased tonic dopamine concentrations observed in the nucleus accumbens using in vivo microdialysis (Tanda et al. 1999). Precipitated withdrawal also induces a significant decrease in phasic dopamine neural activity (Diana et al. 1999). Taken together, these studies show that withdrawal from cannabinoids depresses mesolimbic dopamine function in the same manner as other drugs of abuse.

\section{A BRIEF INTRODUCTION TO THE ENDOCANNABINOID SYSTEM}

The isolation of $\Delta^{9}$-tetrahydrocannabinol from C. sativa (Gaoni and Mechoulam 1964), the discovery that $\Delta^{9}$-tetrahydrocannabinol binds to a G-protein-coupled receptor in the brain (Devane et al. 1988), and the subsequent cloning of the cannabinoid CB1 receptor (Matsuda et al. 1990) led to the elucidation of a previously uncharacterized endogenous cannabinoid, or endocannabinoid system. Anandamide (Devane et al. 1992) and 2-arachydonoylglcycerol (Mechoulam et al. 1995) were the first, and remain the best, characterized endocannabinoids. Based on a growing recognition that cannabinoids modulate mesolimbic dopamine function, the endocannabinoid system is currently receiving a great deal of attention as investigators search for potential pharmacotherapies for addiction (Vries and Schoffelmeer 2005; Justinova et al. 2009).

\section{ENDOCANNABINOIDS MIGHT INCREASE DOPAMINE RELEASE BY DISINHIBITING DOPAMINE NEURAL ACTIVITY}

Lupica's model (Lupica and Riegel 2005) concerning cannabinoid modulation of dopamine neural activity is also relevant in the context of endocannabinoid signaling. Endocannabinoids are unique from classical neurotransmitters in that they are formed and released on demand during periods of high neural activity (Freund et al. 2003). Thus, during phasic dopamine events, intracellular $\mathrm{Ca}^{2+}$ increases precipitously, which then activates enzymes (e.g., diaacylglycerol lipase, DGL) leading to the syn- thesis of endocannabinoids (Wilson and Nicoll 2002; Melis et al. 2004; Alger and Kim 2011). Once synthesized, endocannabinoids traverse the plasma membrane into the extra-synaptic space, where they retrogradely activate cannabinoid CB1 receptors on presynaptic terminals (Wilson and Nicoll 2001). Endocannabinoids binding to presynaptic cannabinoid CB1 receptors is known to result in the suppression of GABA-mediated inhibition (Wilson and Nicoll 2001), a form of synaptic plasticity known as depolarization-induced suppression of inhibition (Alger and Kim 2011). Within the ventral tegmental area, depolarization-induced suppression of inhibition should theoretically result in a net disinhibition of dopamine neural activity (cf. Fig. 2, A vs. B) (Lupica and Riegel 2005). A growing body of evidence suggests that 2-arachydonoylglycerol is the primary endocannabinoid involved in mediating such forms of synaptic plasticity (Melis et al. 2004; Tanimura et al. 2010).

\section{DISRUPTING ENDOCANNABINOID SIGNALING DECREASES DRUG-INDUCED INCREASES IN PHASIC AND TONIC DOPAMINE SIGNALING}

All drugs of abuse increase phasic dopamine events, which theoretically promote drug seeking (Cheer et al. 2007; Aragona et al. 2008). Decreasing drug-induced phasic dopamine events by disrupting endocannabinoid signaling might, therefore, prove to be a successful pharmacological approach for the treatment of addiction (Vries and Schoffelmeer 2005; Solinas et al. 2008). To test whether disrupting endocannabinoid signaling decreases drug-induced phasic dopamine events, Cheer et al. (2007) monitored drug-induced increases in phasic dopamine release events in the nucleus accumbens shell using fast-scan cyclic voltammetry. All drugs assessed, including cocaine, nicotine, and ethanol, increased the frequency of phasic dopamine events. Remarkably, disrupting endocannabinoid signaling by coadministering rimonabant attenuated these drug-induced increases in phasic dopamine release. As illustrated in Figure 3C, cocaine-induced 

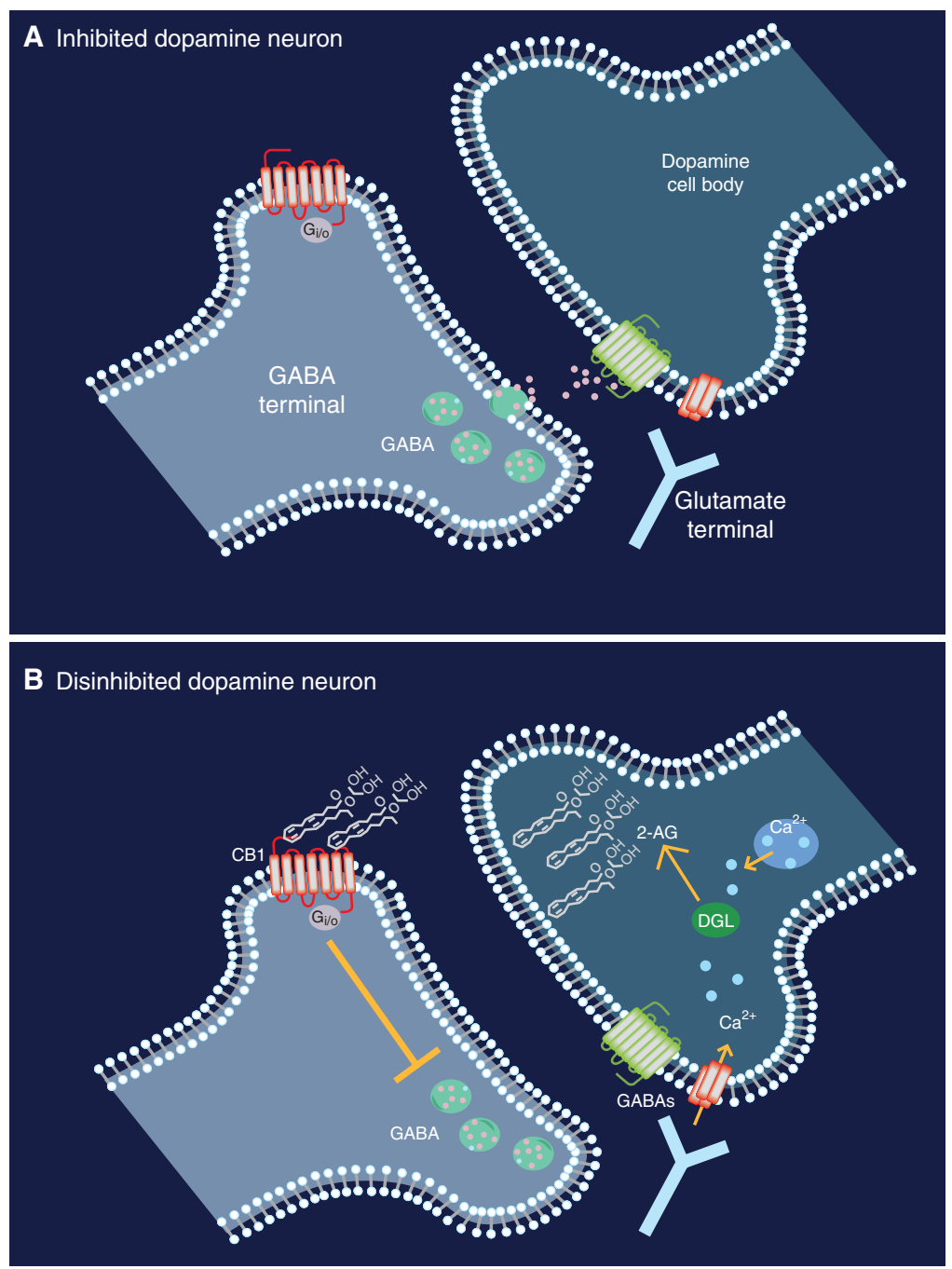

Figure 2. A theoretical microcircuit within the ventral tegmental area showing GABAergic and glutamatergic terminals synapsing onto a dopamine neuron. (A) Under typical conditions, ventral tegmental area dopamine neurons are inhibited via activation of $\mathrm{GABA}_{\mathrm{B}}$ receptors on the dopaminergic neuron. $(B)$ When animals are presented with motivational salient stimuli (e.g., a drug-associated cue), dopamine neurons fire in highfrequency bursts. Consequently, intracellular calcium levels increase, which results in the activation of endocannabinoid synthesizing enzymes (e.g., diacylglycerol lipase, DGL). As a result, 2-arachydonoylglycerol (2-AG) is synthesized and released into the extrasynaptic space. By retrogradely activating $G_{i} / o^{-c o u p l e d ~ c a n n a b i n o i d ~}$ CB1 receptors on GABAergic terminals, GABA release is suppressed. This GABA suppression results in disinhibition of the dopamine neuron, which presumably promotes the occurrence of phasic dopamine events.

increases in phasic dopamine events (top) were diminished by rimonabant (middle) and not observed following vehicle administration alone (bottom). If disrupting endocannabinoid signaling decreases drug-induced phasic dopamine events by preventing the disinhibition of dopamine neural activity within the ventral tegmental area, it should be predicted that tonic dopamine signaling also be suppressed. In accordance with this theory, ethanol-induced increases in tonic accumbal dopamine concentrations are blocked by rimonabant (Hungund 
E.B. Oleson and J.F. Cheer
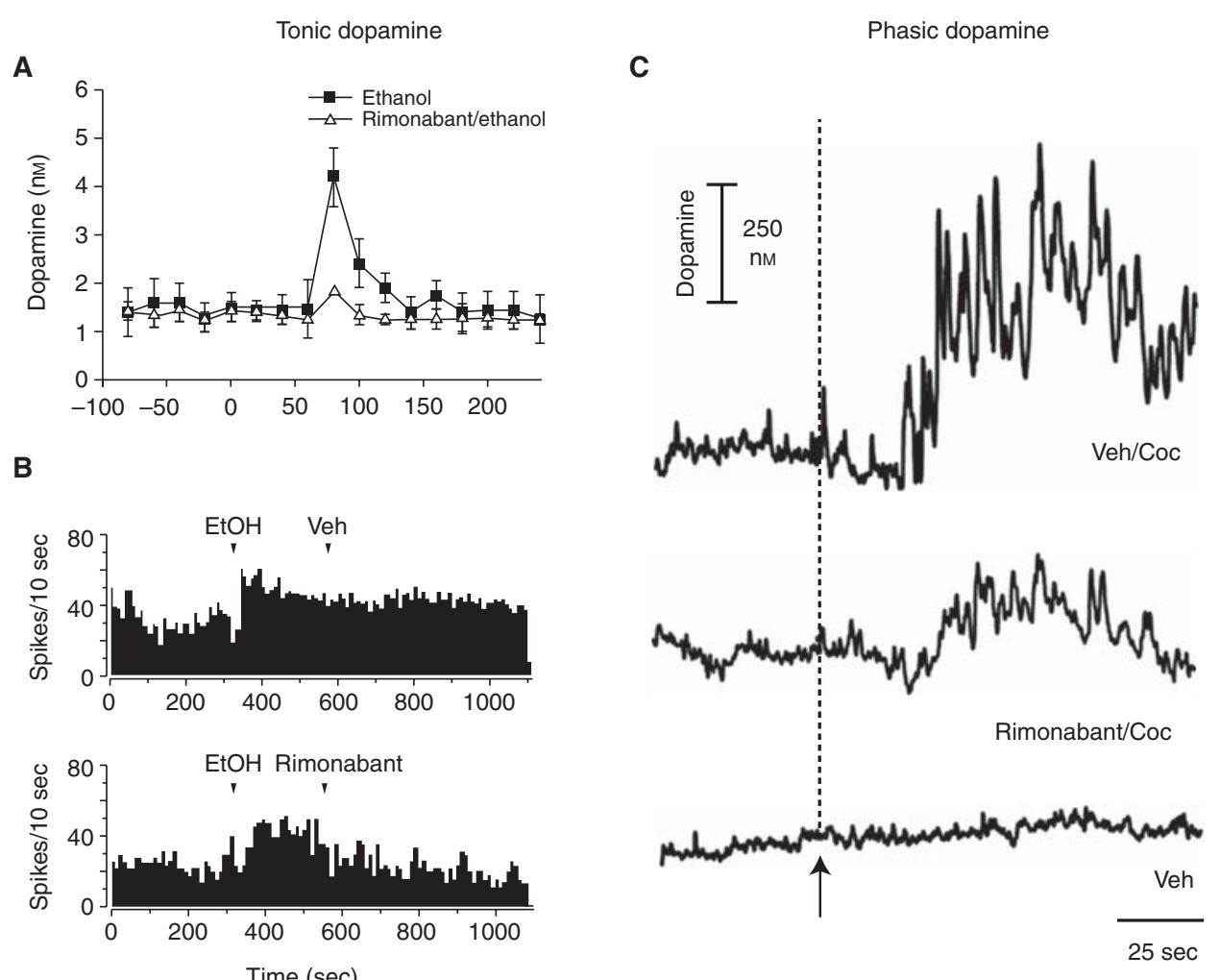

Figure 3. Endocannabinoids are necessary for drug-induced increases in tonic and phasic dopamine release. $(A)$ Endocannabinoids are required for ethanol-induced increases in tonic dopamine concentrations in the nucleus accumbens. When administered independently, ethanol (1.5 g/ kg, filled squares) increased dopamine concentrations. When coadministered with rimonabant $(3 \mathrm{mg} / \mathrm{kg}$ i.p., open triangles), ethanol failed to increase accumbal dopamine concentrations. (Figure constructed from data by Hungund et al. 2003.) (B) Disrupting endocannabinoid signaling with rimonabant $(1 \mathrm{mg} / \mathrm{kg}$ i.v., bottom $)$ reversed ethanol-induced $(0.5 \mathrm{~g} / \mathrm{kg}$ i.v., top) increases in the neural activity of an antidromically identified ventral tegmental area dopamine neuron. (Figure constructed from data by Perra et al. 2005.) (C) Endocannabinoids are required for drug-induced phasic dopamine events. Cocaine ( $3 \mathrm{mg} / \mathrm{kg}$ i.v., top) significantly increased transient increases in nucleus accumbens dopamine concentration. Rimonabant coadministration $(0.3 \mathrm{mg} / \mathrm{kg}$ i.v., middle $)$ significantly attenuated the cocaine-induced increases in phasic dopamine release. Vehicle alone failed to alter phasic dopamine events (bottom). (Figure constructed from data by Cheer et al. 2007.)

et al. 2003). These findings are in agreement with the electrophysiology literature. For example, Pistis and colleagues (Perra et al. 2005) showed that ethanol-induced increases in dopamine neural activity are reduced following rimonabant treatment. Together, these findings support that developing drugs designed to disrupt endocannabinoid signaling might decrease drug-induced increases in phasic dopamine release, which is thought to promote drug seeking, in addition to tonic dopamine release, which is thought to mediate the primary rewarding and reinforcing effects of drugs of abuse.

\section{DISRUPTING ENDOGENOUS CANNABINOID SIGNALING DECREASES CUE-EVOKED DOPAMINE RELEASE}

It is now well accepted that Pavlovian associations formed between drugs of abuse and environmental cues may trigger drug seeking (Childress et al. 1993). In this context, phasic 
dopamine events are thought to encode conditioned stimuli and promote drug seeking (Wheeler and Carelli 2009). It is possible, therefore, that disrupting endocannabinoid signaling might effectively diminish the influence that environmental cues exert over dopamine transmission during reward-directed behavior. A current theory holds that endocannabinoids decrease drug-seeking behavior, in part, by diminishing the secondary/environmental influences of drugs on motivated behavior (Le Foll and Goldberg 2004; Vries and Schoffelmeer 2005). For example, when responding is maintained by drug-associated environmental cues under second-order schedules of reinforcement, rimonabant significantly decreases drug seeking (Justinova et al. 2008). Furthermore, endocannabinoid disruption is particularly effective at reducing cue-induced reinstatement, a model of relapse in humans that incorporates the influence of conditioned environmental stimuli on reward seeking (Epstein et al. 2006). Indeed, rimonabant decreases the propensity for conditioned cues to reinstate responding for various drugs of abuse (Vries and Schoffelmeer 2005; Justinova et al. 2008). To assess whether disrupting endocannabinoid signaling decreases cue-evoked dopamine signaling, Cheer and colleagues (Oleson et al. 2012) treated rats with rimonabant while responding was maintained by brain stimulation reward in a cued intracranial self-stimulation task. Under these conditions, rimonabant significantly decreased cueevoked dopamine release and reward seeking in unison, thereby suggesting that endocannabinoids are critical modulators of dopamine transmission during cue-motivated behavior.

\section{2-ARACHYDONOYLGLYCEROL AND ANANDAMIDE MIGHT DIFFERENTIALLY REGULATE DOPAMINE SIGNALING DURING CUE-MOTIVATED BEHAVIOR}

Although rimonabant clearly decreases dopamine signaling during cue-motivated behavior, whether this is due to a diminished role of 2arachydonoylglycerol and/or anandamide remains unclear. Although it might seem intuitive that both endocannabinoids are involved in promoting dopamine signaling during reward seeking, we now know that this is not the case. On the contrary, multiple studies using pharmacological tools that specifically increase anandamide levels report that these compounds reduce the potency of cues to motivate drugseeking behavior (Scherma et al. 2008; Forget et al. 2009; Gamaleddin et al. 2011). To determine whether such compounds reduce cueevoked dopamine release, Cheer and colleagues (Oleson et al. 2012) tested the effects of VDM11 (a drug that selectively increases anandamide levels in the brain) (Van Der Stelt et al. 2006) under similar behavioral conditions to those in which rimonabant effectively decreased cueevoked dopamine release. As was found following rimonabant treatment, VDM11 uniformly decreased cue-evoked dopamine concentrations and reward seeking. Figure 4 illustrates the effects of VDM11 on accumbal dopamine concentrations across trials as a representative animal is responding for brain stimulation reward in a cued intracranial self-stimulation task. Two dopamine peaks are evident per trial. The first corresponds to the conditioned cue, and the second results from the animal responding for the brain stimulation reward. Note that in response to VDM11, cue-evoked dopamine release decreased, whereas the electrically evoked dopamine peak drifts away from cue presentation and eventually off the temporal scale. The Figure 4 inset depicts a magnified surface plot showing the effects of VDM11 on cue-evoked dopamine events alone. These data support the notion that anandamide decreases dopamine signaling during reward seeking. Moreover, these data indirectly suggest that 2-arachydonoylglycerol is the primary endocannabinoid involved in modulating cue-evoked dopamine release during reward-seeking behavior. In this case, it is possible that anandamide, which is a partial agonist for $\mathrm{CB} 1$ receptors, functions as a competitive antagonist in the presence of 2arachydonoylglycerol, which is a full agonist at CB1 receptors (Howlett and Mukhopadhyay 2000). This conclusion is consistent with the aforementioned observation that 2-arachydonoylglycerol is the primary endocannabinoid involved in mediating synaptic plasticity in 


\section{E.B. Oleson and J.F. Cheer}

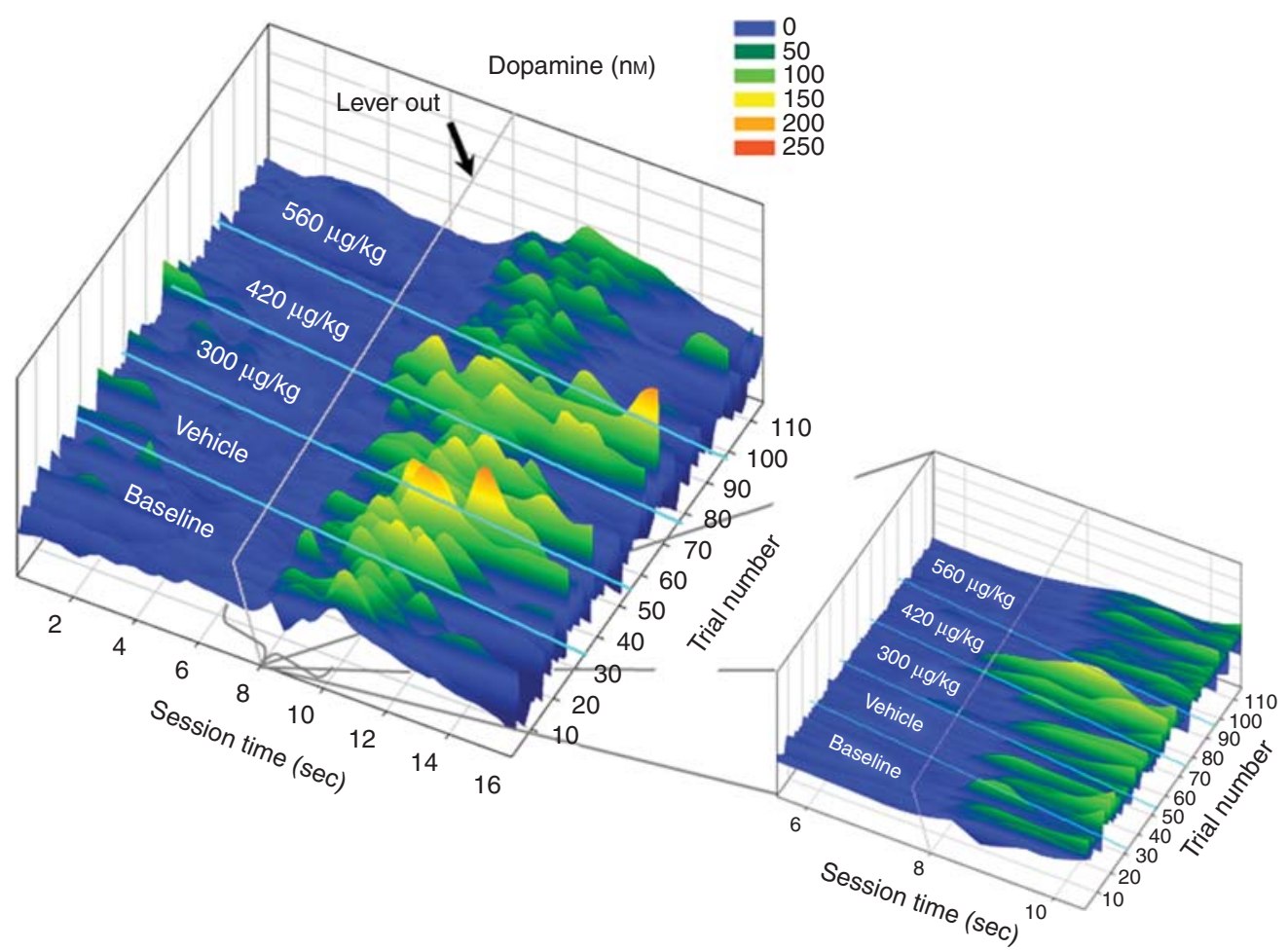

Figure 4. Anandamide decreases cue-evoked dopamine concentrations and reward seeking. A representative surface plot shows changes in dopamine concentration ( $z$-axis) occurring across trials ( $y$-axis) while responding is maintained by brain stimulation reward in a cued intracranial self-stimulation task. VDM11, a drug that selectively increases the endocannabinoid anandamide, dose-dependently decreased phasic dopamine events occurring in response to a reward-predictive cue. As the cue-evoked dopamine concentrations decreased, the behavioral response for brain-stimulation reward shifted away from the conditioned cue. (Figure constructed from data by Oleson et al. 2012.)

multiple brain regions (Melis et al. 2004; Tanimura et al. 2010).

\section{CONCLUDING REMARKS}

Based on the evidence presented herein, commonly abused cannabinoids, such as $\Delta^{9}$-tetrahydrocannabinol, affect the mesolimbic dopamine system similarly to other common drugs of abuse. It is very likely that repeated exposures to $\Delta^{9}$-tetrahydrocannabinol might result in neuroadaptations, not only to the mesolimbic dopamine system, but also to downstream targets that are critically involved in the development of drug addiction. Regarding the endocannabinoid system, we are still in a discovery phase. Little is known concerning the relative contributions of specific endocannabinoids or their exact signaling mechanisms. We are, however, aware of compelling new evidence showing that the endocannabinoid system is capable of modulating the mesolimbic dopamine system and its potential impact in disorders of motivation. Future studies must be conducted to dissect the precise roles of endocannabinoids in this modulation to minimize side effects and how they influence dopamine transmission in animal models.

\section{ACKNOWLEDGMENTS}

This work is supported by NIH grants R01DA022340 and R01DA025890 (to J.F.C.) and F32DA032266 (to E.B.O.). 


\section{REFERENCES}

Aceto MD, Scates SM, Lowe JA, Martin BR. 1995. Cannabinoid precipitated withdrawal by the selective cannabinoid receptor antagonist, SR 141716A. Eur J Pharmacol 282: $\mathrm{R} 1-\mathrm{R} 2$.

Aceto MD, Scates SM, Lowe JA, Martin BR. 1996. Dependence on $\Delta^{9}$-tetrahydrocannabinol: Studies on precipitated and abrupt withdrawal. J Pharmacol Exp Ther 278: $1290-1295$.

Aceto MD, Scates SM, Martin BB. 2001. Spontaneous and precipitated withdrawal with a synthetic cannabinoid, WIN 55212-2. Eur J Pharmacol 416: 75-81.

Alger BE, Kim J. 2011. Supply and demand for endocannabinoids. Trends Neurosci 34: 304-315.

Aragona BJ, Cleaveland NA, Stuber GD, Day JJ, Carelli RM, Wightman RM. 2008. Preferential enhancement of dopamine transmission within the nucleus accumbens shell by cocaine is attributable to a direct increase in phasic dopamine release events. J Neurosci 28: 8821-8831.

Budney AJ, Hughes JR. 2006. The cannabis withdrawal syndrome. Curr Opin Psychiatry 19: 233-238.

Budney AJ, Novy PL, Hughes JR. 1999. Marijuana withdrawal among adults seeking treatment for marijuana dependence. Addiction 94: 1311-1322.

Castaneda E, Moss DE, Oddie SD, Whishaw IQ. 1991. THC does not affect striatal dopamine release: Microdialysis in freely moving rats. Pharmacol Biochem Behav 40: $587-$ 591.

Cheer JF, Marsden CA, Kendall DA, Mason R. 2000. Lack of response suppression follows repeated ventral tegmental cannabinoid administration: An in vitro electrophysiological study. Neuroscience 99: 661-667.

Cheer JF, Wassum KM, Heien ML, Phillips PE, Wightman RM. 2004. Cannabinoids enhance subsecond dopamine release in the nucleus accumbens of awake rats. J Neurosci 24: $4393-4400$.

Cheer JF, Wassum KM, Sombers LA, Heien ML, Ariansen JL, Aragona BJ, Phillips PE, Wightman RM. 2007. Phasic dopamine release evoked by abused substances requires cannabinoid receptor activation. J Neurosci 27: 791-795.

Chen JP, Paredes W, Li J, Smith D, Lowinson J, Gardner EL. 1990. $\Delta^{9}$-Tetrahydrocannabinol produces naloxoneblockable enhancement of presynaptic basal dopamine efflux in nucleus accumbens of conscious, freely-moving rats as measured by intracerebral microdialysis. Psychopharmacology (Berl) 102: 156-162.

Chen JP, Paredes W, Lowinson JH, Gardner EL. 1991. Strainspecific facilitation of dopamine efflux by $\Delta^{9}$-tetrahydrocannabinol in the nucleus accumbens of rat: An in vivo microdialysis study. Neurosci Lett 129: 136-180.

Chen J, Marmur R, Pulles A, Paredes W, Gardner EL. 1993. Ventral tegmental microinjection of $\Delta^{9}$-tetrahydrocannabinol enhances ventral tegmental somatodendritic dopamine levels but not forebrain dopamine levels: Evidence for local neural action by marijuana's psychoactive ingredient. Brain Res 621: 65-70.

Childress AR, McLellan AT, Ehrman R, O’Brien CP. 1988. Classically conditioned responses in opioid and cocaine dependence: A role in relapse. NIDA Res Monogr 84: $25-$ 43.
Childress AR, Hole AV, Ehrman RN, Robbins SJ, McLellan AT, O'Brien CP. 1993. Cue reactivity and cue reactivity interventions in drug dependence. NIDA Res Monogr 137: 73-95.

Devane WA, Dysarz FA, Johnson MR, Melvin LS, Howlett AC. 1988. Determination and characterization of a cannabinoid receptor in rat brain. Mol Pharmacol 34: 605613.

Devane WA, Hanus L, Breuer A, Pertwee RG, Stevenson LA, Griffin G, Gibson D, Mandelbaum A, Etinger A, Mechoulam R. 1992. Isolation and structure of a brain constituent that binds to the cannabinoid receptor. Science 258: $1946-1949$.

Diana M, Muntoni AL, Pistis M, Melis M, Gessa GL. 1999. Lasting reduction in mesolimbic dopamine neuronal activity after morphine withdrawal. Eur J Neurosci 11: 1037-1041.

Di Chiara G, Imperato A. 1988. Drugs abused by humans preferentially increase synaptic dopamine concentrations in the mesolimbic system of freely moving rats. Proc Natl Acad Sci 85: 5274-5278.

Dreyer JK, Herrik KF, Berg RW, Hounsgaard JD. 2010. Influence of phasic and tonic dopamine release on receptor activation. J Neurosci 30: 14273-14283.

Einhorn LC, Johansen PA, White FJ. 1988. Electrophysiological effects of cocaine in the mesoaccumbens dopamine system: Studies in the ventral tegmental area. J Neurosci 8: $100-112$.

Epstein DH, Preston KL, Stewart J, Shaham Y. 2006. Toward a model of drug relapse: An assessment of the validity of the reinstatement procedure. Psychopharmacology (Berl) 189: $1-16$

Forget B, Coen KM, Le Foll B. 2009. Inhibition of fatty acid amide hydrolase reduces reinstatement of nicotine seeking but not break point for nicotine self-administration comparison with CB 1 receptor blockade. Psychopharmacology 205: 613-624.

French ED. 1997. $\Delta$ 9-Tetrahydrocannabinol excites rat VTA dopamine neurons through activation of cannabinoid CB1 but not opioid receptors. Neurosci Lett 226: 159162.

French ED, Dillon K, Wu X. 1997. Cannabinoids excite dopamine neurons in the ventral tegmentum and substantia nigra. Neuroreport 8: 649-652.

Freund TF, Katona I, Piomelli D. 2003. Role of endogenous cannabinoids in synaptic signaling. Physiol Rev 83: 10171066.

Gamaleddin I, Guranda M, Goldberg SR, Le Foll B. 2011. The selective anandamide transport inhibitor VDM11 attenuates reinstatement of nicotine seeking induced by nicotine associated cues and nicotine priming, but does not affect nicotine-intake. Br J Pharmacol 164: 16521660.

Gaoni Y, Mechoulam R. 1964. Isolation, structure, and partial synthesis of an active constituent of hashish. J Am Chem Soc 86: 1646-1647.

Gardner EL. 2002. Addictive potential of cannabinoids: The underlying neurobiology. Chem Phys Lipids 121: 267290. 
E.B. Oleson and J.F. Cheer

Gardner EL. 2005. Endocannabinoid signaling system and brain reward: Emphasis on dopamine. Pharmacol Biochem Behav 81: 263-284.

Gardner EL, Lowinson JH. 1991. Marijuana's interaction with brain reward systems: Update 1991. Pharmacol Biochem Behav 40: 571-580.

Gessa GL, Melis M, Muntoni AL, Diana M. 1998. Cannabinoids activate mesolimbic dopamine neurons by an action on cannabinoid CB1 receptors. Eur J Pharmacol 341: 39-44.

Gonon F. 1988. Nonlinear relationship between impulse flow and dopamine released by rat midbrain dopaminergic neurons as studied by in vivo electrochemistry. $\mathrm{Neu}$ roscience 24: $19-28$.

Grace AA. 1991. Phasic versus tonic dopamine release and the modulation of dopamine system responsivity: A hypothesis for the etiology of schizophrenia. Neuroscience 41: $1-24$.

Haney M, Ward AS, Comer SD, Foltin RW, Fischman MW. 1999. Abstinence symptoms following smoked marijuana in humans. Psychopharmacology 141: 395-404.

Herkenham M, Lynn AB, de Costa BR, Richfield EK. 1991. Neuronal localization of cannabinoid receptors in the basal ganglia of the rat. Brain Res 547: 267-274.

Hershkowitz M, Szechtman H. 1979. Pretreatment with $\Delta^{1}$ tetrahydrocannabinol and psychoactive drugs: Effects on uptake of biogenic amines and on behavior. Eur J Pharmacol 59: 267-276.

Howlett AC, Mukhopadhyay S. 2000. Cellular signal transduction by anandamide and 2-arachidonoylglycerol. Chem Phys Lipids 108: 53-70.

Hungund BL, Szakall I, Adam A, Basavarajappa BS, Vadasz C. 2003. Cannabinoid CB1 receptor knockout mice exhibit markedly reduced voluntary alcohol consumption and lack alcohol induced dopamine release in the nucleus accumbens. J Neurochem 84: 698-704.

Jones RT, Benowitz N, Bachman J. 1976. Clinical studies of cannabis tolerance and dependence. Ann NY Acad Sci 282: $221-239$.

Julian MD, Martin AB, Cuellar B, Rodriguez De Fonseca F, Navarro M, Moratalla R, Garcia-Segura LM. 2003. Neuroanatomical relationship between type 1 cannabinoid receptors and dopaminergic systems in the rat basal ganglia. Neuroscience 119: 309-318.

Justinova Z, Munzar P, Panlilio L, Yasar S, Redhi G, Tanda G, Goldberg S. 2008. Blockade of THC-seeking behavior and relapse in monkeys by the cannabinoid CB1-receptor antagonist rimonabant. Neuropsychopharmacology 33: $2870-2877$.

Justinova Z, Panlilio LV, Goldberg SR. 2009. Drug addiction. Curr Top Behav Neurosci 1: 309-346.

Koob GF. 2009. Neurobiological substrates for the dark side of compulsivity in addiction. Neuropharmacology 56: $18-31$.

Koob GF, Sanna PP, Bloom FE. 1998. Neuroscience of addiction. Review. Neuron 21: 461-476.

Le Foll B, Goldberg S. 2004. Rimonabant, a CB1 antagonist, blocks nicotine-conditioned place preferences. Neuroreport 15: 2139-2143.
Lichtman AH, Martin BR. 2002. Marijuana withdrawal syndrome in the animal model. J Clin Pharmacol 42: 20S27S.

Lupica CR, Riegel AC. 2005. Endocannabinoid release from midbrain dopamine neurons: A potential substrate for cannabinoid receptor antagonist treatment of addiction. Neuropharmacology 48: 1105-1116.

Malone DT, Taylor DA. 1999. Modulation by fluoxetine of striatal dopamine release following $\Delta^{9}$-tetrahydrocannabinol: A microdialysis study in conscious rats. $\mathrm{Br} \mathrm{J}$ Pharmacol 128: 21-26.

Matsuda LA, Lolait SJ, Brownstein MJ, Young AC, Bonner TI. 1990. Structure of a cannabinoid receptor and functional expression of the cloned cDNA. Nature 346: 561564.

Mechoulam R, Ben-Shabat S, Hanus L, Ligumsky M, Kaminski NE, Schatz AR, Gopher A, Almog S, Martin BR, Compton DR. 1995. Identification of an endogenous 2monoglyceride, present in canine gut, that binds to cannabinoid receptors. Biochem Pharmacol 50: 83-90.

Melis M, Pistis M, Perra S, Muntoni AL, Pillolla G, Gessa GL. 2004. Endocannabinoids mediate presynaptic inhibition of glutamatergic transmission in rat ventral tegmental area dopamine neurons through activation of $\mathrm{CB} 1$ receptors. J Neurosci 24: 53-62.

Ng Cheong Ton JM, Gerhardt GA, Friedemann M, Etgen AM, Rose GM, Sharpless NS, Gardner EL. 1988. The effects of $\Delta^{9}$-tetrahydrocannabinol on potassium-evoked release of dopamine in the rat caudate nucleus: An in vivo electrochemical and in vivo microdialysis study. Brain Res 451: 59-68.

Oleson EB, Beckert MV, Morra JT, Lansink CS, Cachope R, Abdullah RA, Loriaux AL, Schetters D, Pattij T, Roitman MF, et al. 2012. Endocannabinoids shape accumbal encoding of cue-motivated behavior via CB1 receptor activation in the ventral tegmentum. Neuron 73: 360-373.

Owesson-White CA, Ariansen J, Stuber GD, Cleaveland NA, Cheer JF, Wightman RM, Carelli RM. 2009. Neural encoding of cocaine-seeking behavior is coincident with phasic dopamine release in the accumbens core and shell. Eur J Neurosci 30: 1117-1127.

Perra S, Pillolla G, Melis M, Muntoni AL, Gessa GL, Pistis M. 2005. Involvement of the endogenous cannabinoid system in the effects of alcohol in the mesolimbic reward circuit: Electrophysiological evidence in vivo. Psychopharmacology (Berl) 183: 368-377.

Phillips PE, Stuber GD, Heien ML, Wightman RM, Carelli RM. 2003. Subsecond dopamine release promotes cocaine seeking. Nature 422: 614-618.

Pierce RC, Kumaresan V. 2006. The mesolimbic dopamine system: The final common pathway for the reinforcing effect of drugs of abuse? Neurosci Biobehav Rev 30: 215 238.

Poddar MK, Dewey WL. 1980. Effects of cannabinoids on catecholamine uptake and release in hypothalamic and striatal synaptosomes. J Pharmacol Exp Ther 214: 63-67.

Ritz MC, Lamb RJ, Goldberg SR, Kuhar MJ. 1987. Cocaine receptors on dopamine transporters are related to selfadministration of cocaine. Science 237: 1219-1223.

Roberts DC, Corcoran ME, Fibiger HC. 1977. On the role of ascending catecholaminergic systems in intravenous self- 
administration of cocaine. Pharmacol Biochem Behav 6: 615-620.

Rossetti ZL, Hmaidan Y, Gessa GL. 1992. Marked inhibition of mesolimbic dopamine release: A common feature of ethanol, morphine, cocaine and amphetamine abstinence in rats. Eur J Pharmacol 221: 227-234.

Scherma M, Medalie J, Fratta W, Vadivel SK, Makriyannis A, Piomelli D, Mikics E, Haller J, Yasar S, Tanda G. 2008. The endogenous cannabinoid anandamide has effects on motivation and anxiety that are revealed by fatty acid amide hydrolase (FAAH) inhibition. Neuropharmacology 54: 129-140.

Solinas M, Goldberg SR, Piomelli D. 2008. The endocannabinoid system in brain reward processes. Br J Pharmacol 154: 369-383.

Sombers LA, Beyene M, Carelli RM, Wightman RM. 2009. Synaptic overflow of dopamine in the nucleus accumbens arises from neuronal activity in the ventral tegmental area. J Neurosci 29: 1735-1742.

Spanagel R, Weiss F. 1999. The dopamine hypothesis of reward: Past and current status. Trends Neurosci 22: 521-527.

Szabo B, Siemes S, Wallmichrath I. 2002. Inhibition of GABAergic neurotransmission in the ventral tegmental area by cannabinoids. Eur J Neurosci 15: 2057-2061.

Tanda G, Pontieri FE, Di Chiara G. 1997. Cannabinoid and heroin activation of mesolimbic dopamine transmission by a common $\mu 1$ opioid receptor mechanism. Science 276: $2048-2050$.

Tanda G, Loddo P, Di Chiara G. 1999. Dependence of mesolimbic dopamine transmission on $\Delta^{9}$-tetrahydrocannabinol. Eur J Pharmacol 376: 23-26.

Tanimura A, Yamazaki M, Hashimotodani Y, Uchigashima M, Kawata S, Abe M, Kita Y, Hashimoto K, Shimizu T, Watanabe M, et al. 2010. The endocannabinoid 2-arachidonoylglycerol produced by diacylglycerol lipase $\alpha$ mediates retrograde suppression of synaptic transmission. Neuron 65: 320-327.

Todd A. 1946. Hashish. Experientia 2: 55-60.

Tsou K, Patrick SL, Walker JM. 1995. Physical withdrawal in rats tolerant to $\Delta^{9}$-tetrahydrocannabinol precipitated by a cannabinoid receptor antagonist. Eur J Pharmacol 280: R13-R15.

Van Der Stelt M, Mazzola C, Esposito G, Matias I, Petrosino S, Filippis DD, Micale V, Steardo L, Drago F, Iuvone T. 2006. Endocannabinoids and $\beta$-amyloid-induced neurotoxicity in vivo: Effect of pharmacological elevation of endocannabinoid levels. Cell Mol Life Sci 63: 1410-1424.

Vries T, Schoffelmeer A. 2005. Cannabinoid CB1 receptors control conditioned drug seeking. Trends Pharmacol Sci 26: $420-426$.

Weiss F, Markou A, Lorang MT, Koob GF. 1992. Basal extracellular dopamine levels in the nucleus accumbens are decreased during cocaine withdrawal after unlimited-access self-administration. Brain Res 593: 314-318.

Weiss F, Parsons LH, Schulteis G, Hyyti P, Lorang MT, Bloom FE, Koob GF. 1996. Ethanol self-administration restores withdrawal-associated deficiencies in accumbal dopamine and 5-hydroxytryptamine release in dependent rats. J Neurosci 16: 3474-3485.

Weiss F, Ciccocioppo R, Parsons LH, Katner S, Liu X, Zorrilla EP, Valdez GR, Ben-Shahar O, Angeletti S, Richter RR. 2001. Compulsive drug-seeking behavior and relapse. Neuroadaptation, stress, and conditioning factors. Ann NY Acad Sci 937: 1-26.

Wheeler RA, Carelli RM. 2009. Dissecting motivational circuitry to understand substance abuse. Neuropharmacology 56: $149-159$.

Wickelgren I. 1997. Marijuana: Harder than thought? Science 276: 1967-1968.

Wilson RI, Nicoll RA. 2001. Endogenous cannabinoids mediate retrograde signalling at hippocampal synapses. $\mathrm{Na}$ ture 410: 588-592.

Wilson RI, Nicoll RA. 2002. Endocannabinoid signaling in the brain. Science 296: 678-682.

Wise RA, Bozarth MA. 1985. Brain mechanisms of drug reward and euphoria. Psychiatr Med 3: 445-460.

Wu X, French ED. 2000. Effects of chronic $\Delta^{9}$-tetrahydrocannabinol on rat midbrain dopamine neurons: An electrophysiological assessment. Neuropharmacology 39: 391-398. 


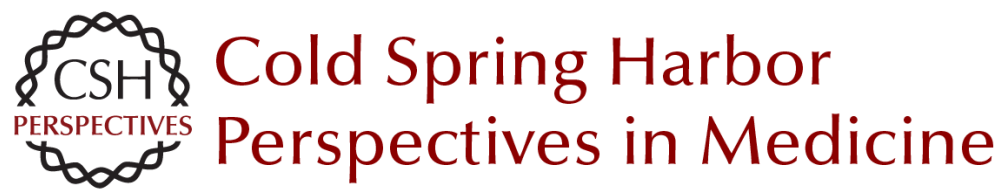

\section{A Brain on Cannabinoids: The Role of Dopamine Release in Reward Seeking}

Erik B. Oleson and Joseph F. Cheer

Cold Spring Harb Perspect Med 2012; doi: 10.1101/cshperspect.a012229

Subject Collection

For additional articles in this collection, see http://perspectivesinmedicine.cshlp.org/cgi/collection/ 